\title{
Flux Decline in Ultrafiltration Processes
}

\author{
G.B. VAN DEN BERG and C.A. SMOLDERS \\ Department of Chemical Technology, University of Twente, P.O. Box 217, 7500 AE \\ Enschede (The Netherlands) Tel. 31-53-89295110 Fax 31-53-356024
}

\section{SUMMARY}

When a membrane filtration process such as ultrafiltration is used a flux- and yield-decline can be observed. The causes are i) concentration polarization (i.e. accumulation of retained solutes, reversibly and immediately occurring) and ii) fouling phenomena such as adsorption, pore-blocking and deposition of solidified solutes, a long-term, and more or less irreversible process. The result of both these phenomena are a decreasing driving force for the filtration or an increasing resistance against transport of the permeating solvent during the filtration. The degree of flux decline depends on many variables, both solution and equipment related.

Several models have been developed to describe the polarization phenomena, in general they can be subdivided in (A) resistance models, (B) gel-polarization models and (C) osmotic pressure models. A new boundary layer resistance model for unstirred dead-end ultrafiltration is described more in detail. This model can predict fluxes and related phenomena; the simulations agree very well with the experimental data.

The flux decline behaviour of binary mixtures of equally and unequally charged proteins ( $\alpha$-lactalbumin, BSA and lysozyme) was studied. In case the mixture consists of oppositely charged proteins a considerable increase of the resistance of the concentrated layer near the membrane interface can be observed, which depends on the mixing ratio of the proteins. When equally charged proteins are filtered the resistance decreases a little, again depending on the mixing ratio.

Several methods exist to improve the flux, they can be generally divided into: (1) adapting the operation conditions in the existing equipment, (2) altering the conditions in the solution, (3) using a different or pretreated membrane, (4) taking additional measures to prevent or decrease the flux decline. 


\section{SYMBOLS}

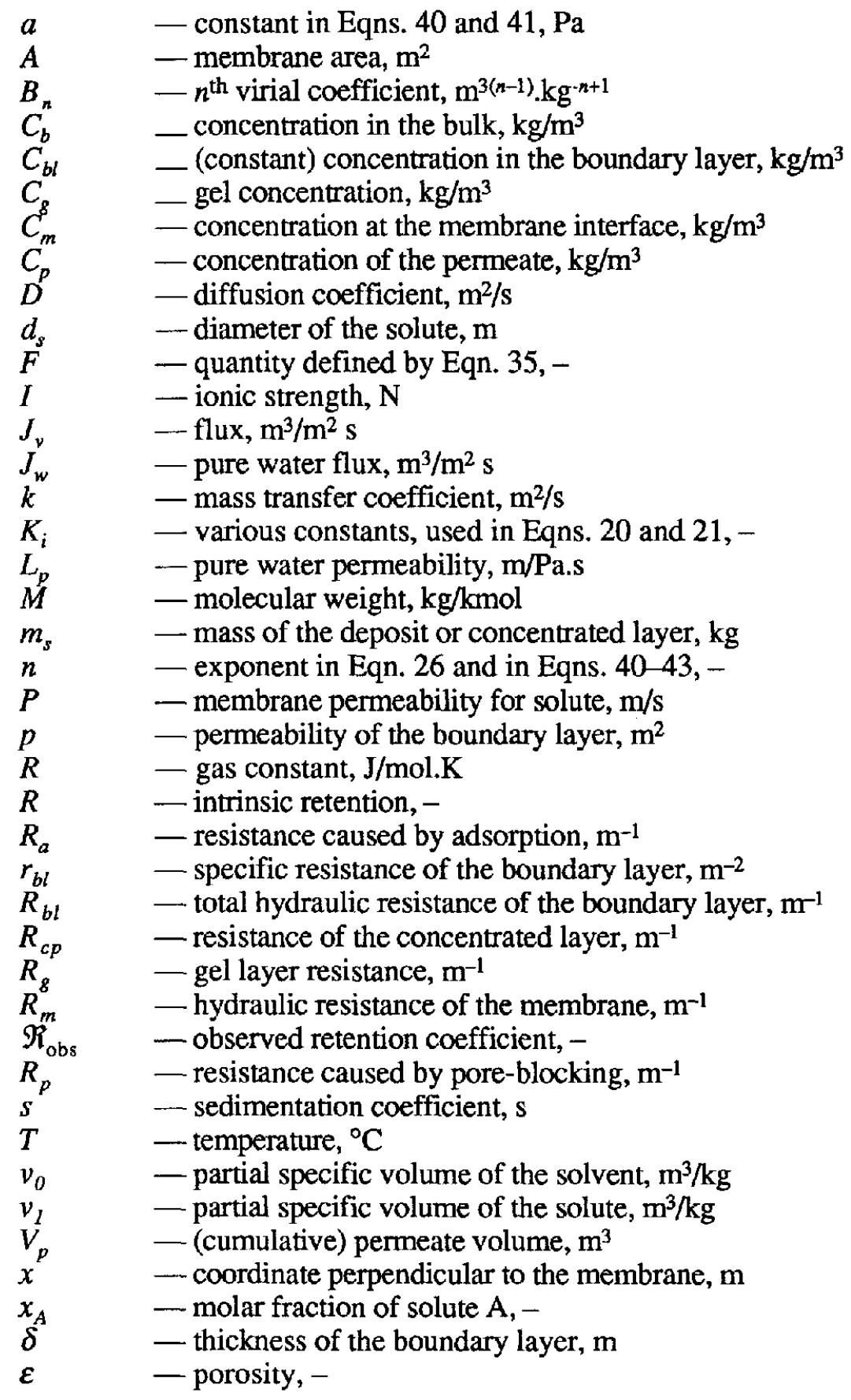




$\begin{array}{ll}\Delta P & \text { - applied pressure, } \mathrm{Pa} \\ \eta_{0} & \text { - viscosity of the solvent, } \mathrm{Pa} . \mathrm{s} \\ \pi & \text { - osmotic pressure, } \mathrm{Pa} \\ \sigma & \text { - reflection coefficient, } \\ \rho & \text { - density, } \mathrm{kg} \cdot \mathrm{m}^{-3}\end{array}$

\section{INTRODUCTION}

Since the first asymmetric reverse osmosis membranes became available in the early sixties membrane technology has developed enormously. This is expressed in the vast amount of research which has gone into developing the right membrane type and module for different kinds of separation processes, developing new processes as well as researching the best possible circumstances for the separation. These efforts have resulted in the present day commercialization of ultrafiltration (UF), microfiltration (MF), reverse osmosis or hyperfiltration (RO), gas separation, (kidney-) dialysis and electrodialysis (ED).

Some applications of these techniques are:

- Food industry: whey processing (RO and UF), concentration of milk for cheese production (UF), clarification and/or sterilization of various fluids such as wine, vinegar and apple juice (MF) and whey desalting (ED).

- Water treatment: production of high resistivity $(>18 \mathrm{M} \Omega / \mathrm{cm})$ water for the electronics industry (MF and RO) and production of clean boiler feedwater, potable water and clean waste water (RO and ED).

- Others: oil-water separation (UF and MF), recovery of paint and latices from waste water effluents (UF), hemo-dialysis, membrane electrolysis and the recovery of gases (GS).

\section{FLUX DECLINE}

One of the most important reasons that membrane processes are not used on a much larger scale is the flux decline during the process. Flux decline is caused by several phenomena in, on and near the membrane. These phenomena can also cause a loss in selectivity or an additional undesired selectivity. The flux decline, related to the so called pure water flux, can be a few procent of the pure water flux for relatively clean feeds in UF, up to more than $90 \%$ decline in flux in some cases of MF. The reasons for the flux decline will be different in each case of filtration. In general, the flux decline is caused by a decreased driving force and/or an increased resistance. 
The flux $J_{v}$ can be described by:

flux $J_{v}=\frac{\mathrm{d} V}{A \cdot \mathrm{d} t}=\frac{\text { driving force (e.g. } \Delta P, \Delta C \text { or } \Delta T)}{\text { viscosity }{ }^{*} \text { total resistance }}$

The resistances which can occur during a filtration process are schematically represented in Fig. 1.

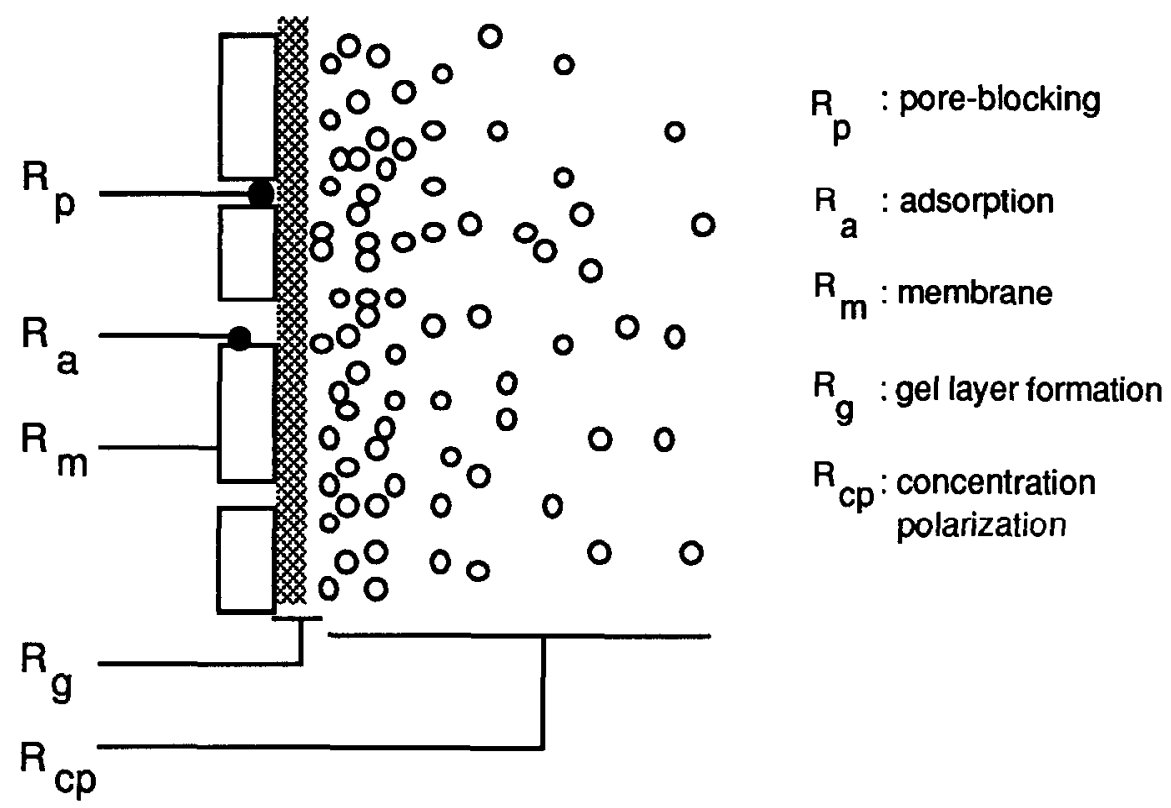

Fig. 1. Possible resistances against solvent transport.

Except for the resistance of the membrane $R_{m}$ which is always present, resistances can occur because of pores being blocked by the solute $\left(R_{p}\right)$. Furthermore, adsorption of the solute onto the walls of the pores of the membrane will also result in a less permeable membrane $\left(R_{a}\right)$. Another, very important, phenomenon is the so-called concentration polarization. Because of the solute being retained by the membrane and the solvent passing the membrane the solute will accumulate to form a layer at the membrane interface with a relatively high concentration. The concentrated layer near the membrane is less permeable for the solvent (usually water) in comparison with an unaltered solution, which is expressed by an additional resistance $R_{c p}$. This phenomenon in parallel results in a (much) higher osmotic pressure $\Delta \pi$ at the membrane interface, even for cases where macromolecular solutions are used, and leads to a decrease in the driving force which then becomes $\Delta P-\Delta \pi$. Finally, the 
concentration at the membrane interface can reach such high values that the concentrated solution will change into a gel with a resistance $R_{g}$. Gel layer formation occurs easily with protein containing liquids.

The flux decline phenomena can be generally divided in fouling (irreversible and long term phenomena) and concentration polarization (reversible and directly occuring phenomena).

Apart from the phenomena mentioned above, additional effects can be expected when the solutes in the solution show mutual interactions. Especially the difference in charge of the solutes can contribute to a deviating behaviour of the solution.

The effects of adsorbed proteins has been studied by several researchers [14]. In general it is found that the amount adsorbed depends on the membrane material, the solute type, the concentration and in case of proteins on the ionic strength and the $\mathrm{pH}$. The adsorption will increase with increasing concentration and, in case of proteins, will increase at $\mathrm{pH}$-values closer to the isoelectric point. Hydrophobic membranes (polysulfone, polypropylene, polytetrafluoroethylene) adsorb more proteins than hydrophilic membranes (cellulose acetate, polyacrylonitrile). This can be the reason for choosing a hydrophilic membrane for a separation process involving proteins. Disadvantages of these hydrophilic membranes often are a limited chemical and temperature resistivity.

Deposition of solutes onto the membrane surface will also decrease the flux. The deposition can be caused by e.g. the aggregation of proteins, even at low concentrations (lower than the gel concentration) or by precipitation of saturated salt solutions. In the first case a long-term time-dependent flux decline is shown to occur during filtration of diluted (single) protein solutions by aggregate formation [5]. Also interaction between positive and negative proteins will lead to aggregation [6]. A salt like calciumphosphate is known to cause a flux decline during the filtration of milk and whey when the temperature and $\mathrm{pH}$ are not chosen correctly. This process is called scaling and it can also occur inside the membrane. Reviews of fouling and fouling control are given by several authors $[7,8]$.

\section{CONCENTRATION POLARIZATION PHENOMENA}

The build-up of solute near the membrane interface can be described in two ways: either by the cake-filtration type of description or by a description according to the film theory (Fig. 2).

Models according to the cake-filtration theory assume a constant concentration in the layer near the membrane, which sometimes depends on the applied pressure and which increases in thickness with increasing permeate 
volume. For unstirred dead-end filtration conditions this concentration in the boundary layer can be calculated from the mass balance

$C_{b} \cdot \Re_{\mathrm{obs}} \cdot V_{p}=\delta \cdot A \cdot C_{b l}$

where $C_{b}$ is the concentration in the bulk of the solution, $\Re_{\mathrm{obs}}$ is the observed retention (defined by $\Re_{o b s}=\left[1-\left(C_{p /} / C_{b}\right)\right], V_{p}$ is the total permeate volume, $A$ is the membrane area and $\delta$ is the thickness of the boundary layer. We use the equation for the flux

$J_{v}=\frac{\Delta P}{\eta_{0}\left(R_{m}+R_{b l}\right)}$

where $\eta_{0}$ is the viscosity of the solvent and $R_{b l}$ is the resistance of the concentrated boundary layer. Together with the equation for the total resistance of the boundary layer

$R_{b l}=\delta \cdot r_{b l}$

where $r_{b l}$ is the specific resistance of the boundary layer, one obtains

$\frac{1}{J_{v}}=\frac{1}{J_{w}}+\left(\frac{\eta_{0} C_{b} \Re_{\mathrm{obs}}}{\Delta P}\right) \cdot\left(\frac{r_{b l}}{C_{b l}}\right) \cdot\left(\frac{V_{p}}{A}\right)$

where $J_{w}$ is the pure water flux. Integration of Eqn. 5, with $J_{v}=\mathrm{d} V_{p} / A \mathrm{~d} t$, leads to

$t=\left(\frac{\eta_{0} C_{b} \Re_{o b s}}{\Delta P}\right) \cdot\left(\frac{r_{b l}}{C_{b l}}\right) \cdot\left(\frac{V_{p}}{A}\right)^{2}$

which results in the well-known relationships for unstirred dead-end filtration $V_{p} \sim t^{0.5}$ or $J_{v} \sim t^{0.5}$. The various methods to calculate the specific resistance of the boundary layer will be described in the paragraph on resistance models. The cake filtration type of description is also used in some methods to characterize the fouling capacity of a solution. By unstirred dead-end filtration of the solution during a fixed time a fouling index can be calculated for the solution, which is then used for further research $[9,10]$.

In Figs. 3 and 4 typical unstirred dead-end filtration plots are represented. The reciprocal flux indeed is linear to the permeate volume. Different slopes are obtained when different concentrations or pressures are used. In Fig. 5 the flux is given as a function of time and shows the $J_{v} \sim t^{-0.5}$ relationship. 


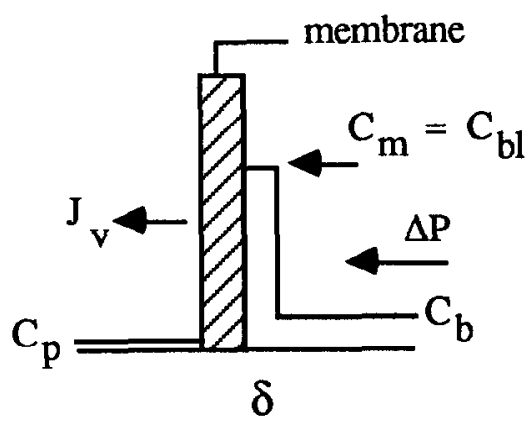

a) the cake-filtration type of description

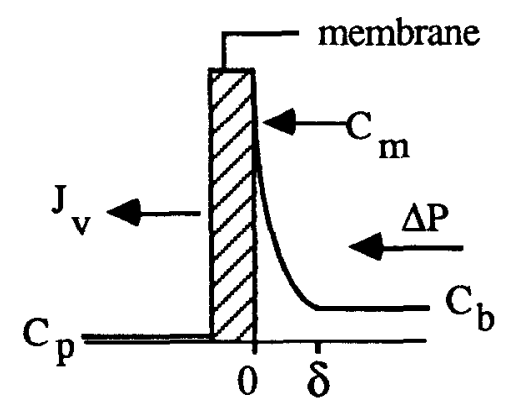

b) the concentration profile according to the film theory

Fig. 2. The concentration profiles due to concentration polarization according to the cakefiltration type of description (a) and the film theory (b).

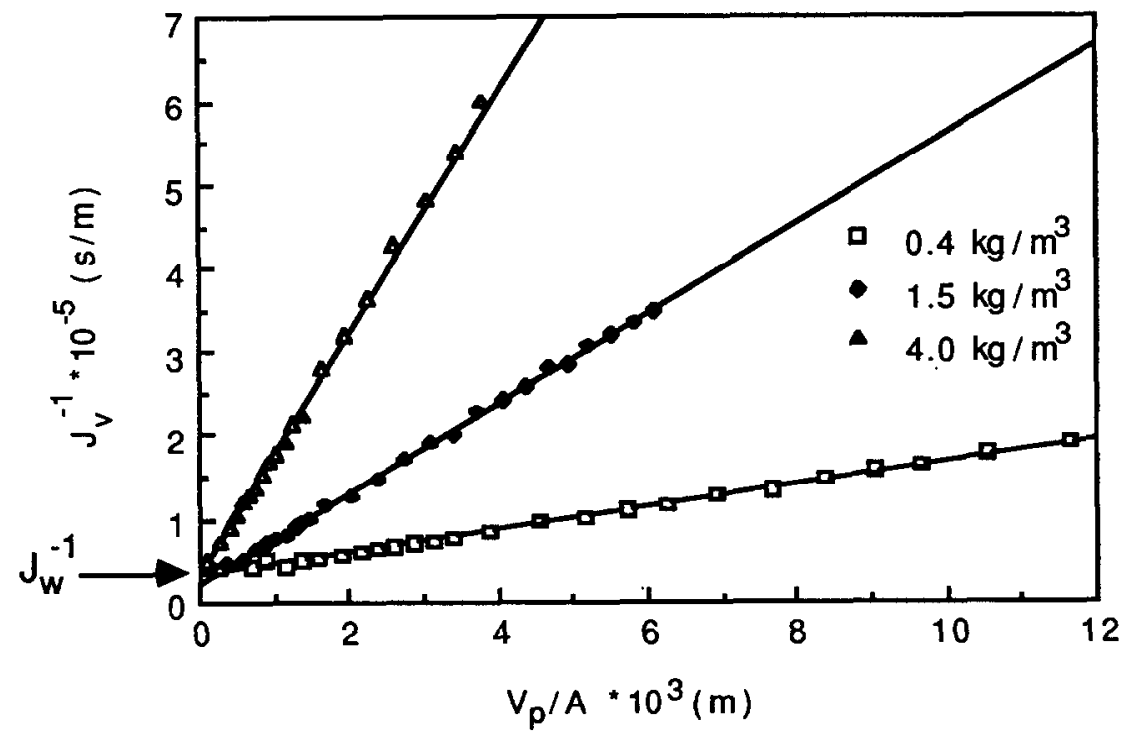

Fig. 3. The reciprocal flux as a function of the permeate volume at different concentrations (unstirred dead-end UF of BSA at $\Delta P=1.010^{5} \mathrm{~Pa}$ ). 


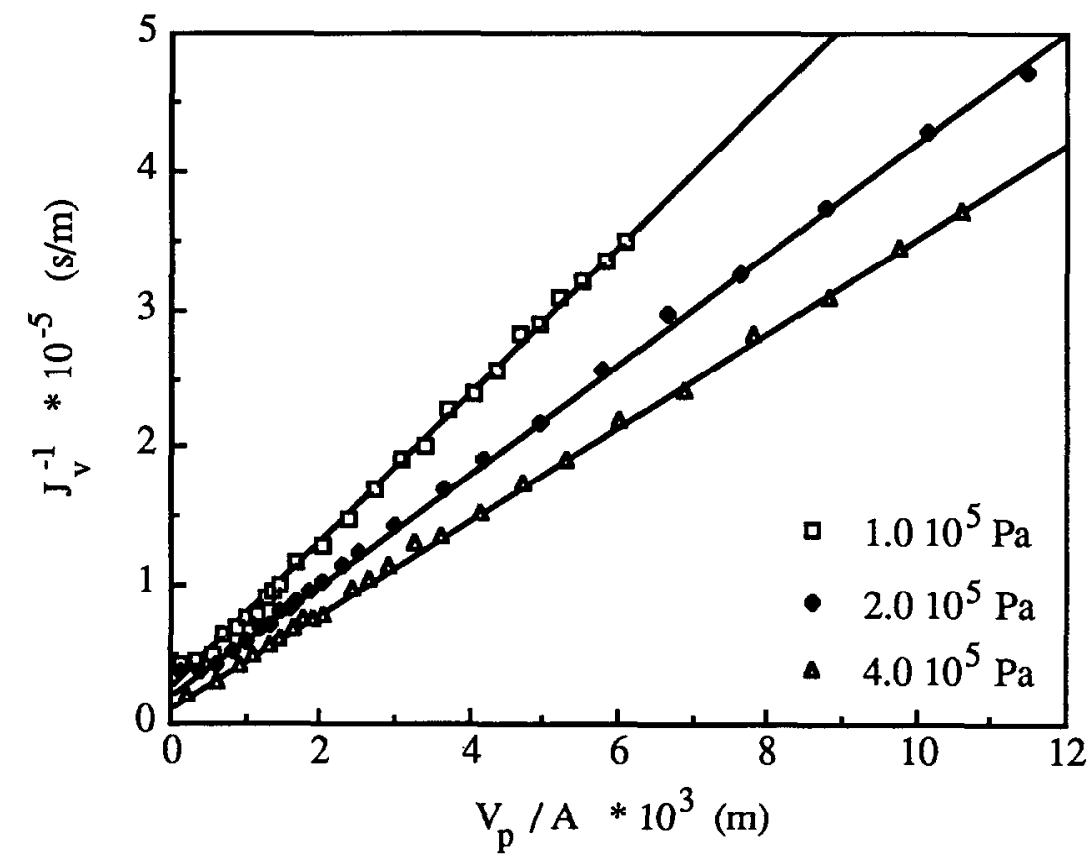

Fig. 4. The reciprocal flux as a function of the permeate volume at different applied pressures (unstirred dead-end UF of BSA with $C_{b}=1.5 \mathrm{~kg} / \mathrm{m}^{3}$ ).

Models which describe the concentration polarization phenomenon by the film theory (see Fig. 2) usually start from a basic equation like

$\frac{\partial C}{\partial t}+J_{v} \frac{\partial C}{\partial x}=\partial\left(D \cdot \frac{\partial C}{\partial x}\right) / \partial x$

where $J_{v} \partial C / \partial x$ represents the convective transport towards the membrane, while $\partial(D \cdot \partial C / \partial x) / \partial x$ represents the back-diffusion as a result of the concentration gradient. This differential equation has to be solved, analytically or numerically, knowing that for some solutes the diffusion coefficient is a function of the concentration. In some cases the diffusion coefficient must represent the diffusion of a large number of solutes, e.g. when a liquid like milk is filtered.

When the diffusion coefficient is constant Eqn. 7 becomes

$$
\frac{\partial C}{\partial t}+J_{v} \frac{\partial C}{\partial x}=D \cdot \frac{\partial^{2} C}{\partial x^{2}}
$$


Normally the starting and boundary conditions are:

$$
\begin{array}{ll}
t=0 & : C=C_{b} \\
x=\delta & : C=C_{b} \\
x=0 & : J_{v} \cdot C_{m}=D \cdot(\partial C / \partial x)_{x=0}+\left(1-\Re_{\mathrm{obs}}\right) \cdot J_{v} \cdot C_{b} \\
\text { or } & J_{v} \cdot\left(C_{m}-C_{p}\right)=D \cdot(\partial C / \partial x)_{x=0}
\end{array}
$$

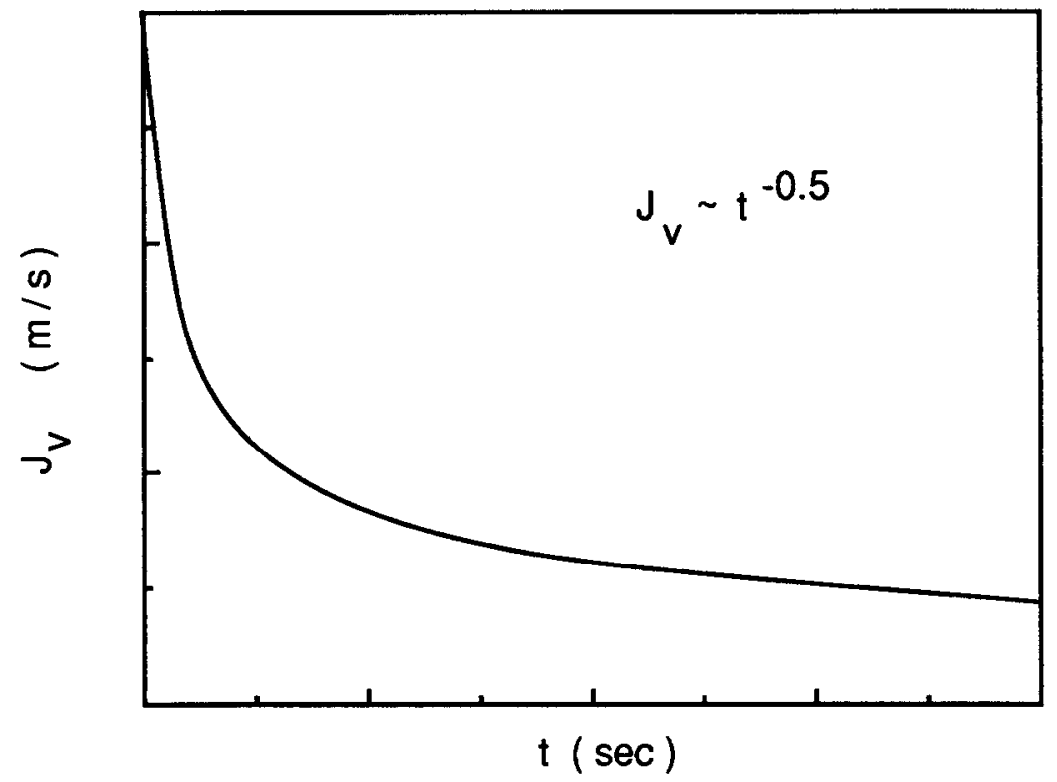

Fig. 5. Typical flux behaviour during unstirred dead-end filtration.

In a steady state situation, which is reached after some time in stirred deadend and cross-flow filtration, Eqn. 8 results in the well-known film-theory relationship

$J_{v}=\left(\frac{D}{\delta}\right) \cdot \ln \left\{\frac{\left(C_{m}-C_{p}\right)}{\left(C_{b}-C_{p}\right)}\right\}$

The quantity $D / \delta$ is called the mass transfer coefficient $k$, which is solute and equipment dependent. When the retention equals unity the concentration function for the boundary layer can be described by 
$C_{(\delta-x)}=C_{b} \cdot \exp \left(\frac{J_{v} \cdot(\delta-x)}{D}\right)$

In Fig. 6 the steady-state flux is represented as a function of the applied pressure. These curves are schematic representations of typical experimental findings, when macromolecular or colloidal solutions are being ultrafiltered. The flux first increases with increasing pressure and finally becomes constant: leading to a pressure-independent filtration. The influence of increasing concentration is given, which is inversely effective compared to the influence of increasing mass transfer coefficients.

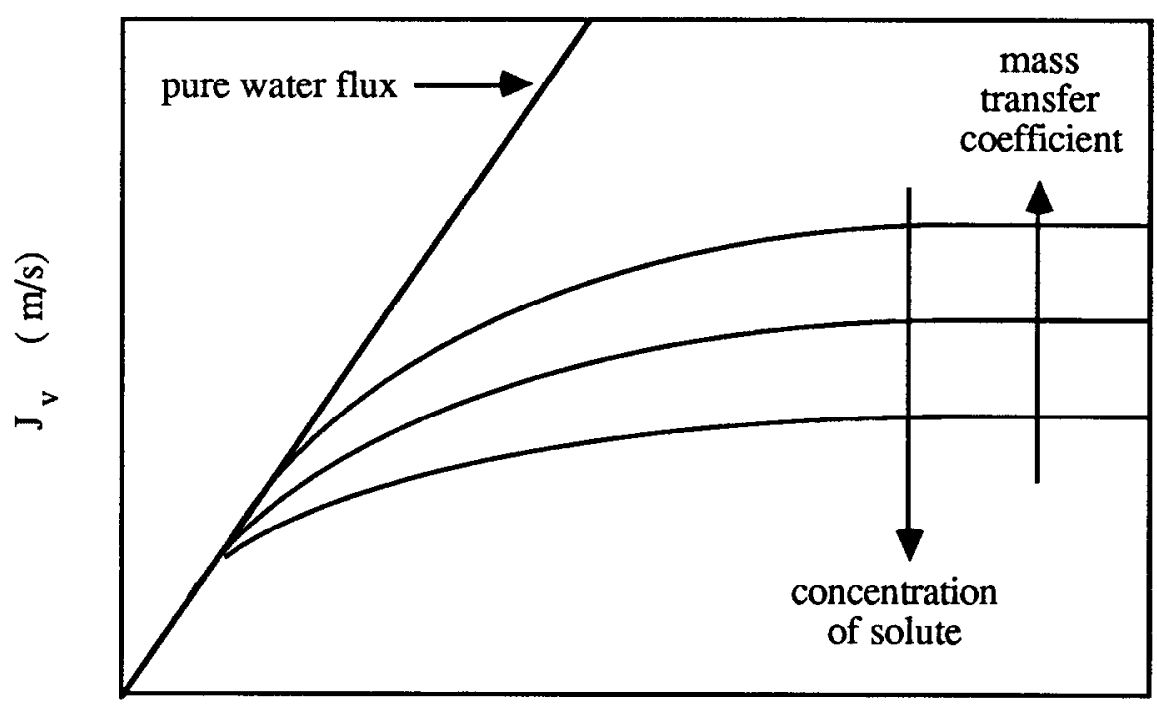

$\Delta \mathrm{P}(\mathrm{Pa})$

Fig. 6. Steady state fluxes during cross-flow filtration of a macromolecular solute as a function of the applied pressure. Both the influence of increasing solute concentrations and the influence of increasing mass transfer coefficients is represented.

Both for the cake-filtration type of description and for the dynamic description according to the film theory several different models exist in literature to cover the effect of the concentration polarization phenomena. These models can be subdivided in A) resistance models, B) gel-polarization models and C) osmotic pressure models.

There are two kinds of resistance models: filtration models (A1) and boundary layer resistance models (A2). The filtration models often use the well- 
known Kozeny-Carman relationship to calculate the specific resistance of a cake with a constant concentration. These models are used mostly when colloids are filtered. The boundary layer models use the relationship between the permeability of a concentrated layer for the solvent and the sedimentation of solute at high concentrations to calculate the specific resistance. They exist for both unstirred dead-end and cross-flow filtration.

The gel-polarization models are available for all varieties of filtration methods. Sometimes the gel concentration is difficult to determine, while the diffusivity up to the gel concentration often is assumed to be constant (e.g. equal to the diffusivity at the bulk concentration).

The osmotic pressure models use the decrease in the driving force by the osmotic effects to calculate the flux. Mostly the osmotic pressure $\pi$ of concentrated solutions is determined experimentally, though for simple solutions $\pi$ can also be calculated.

All the models mentioned above were derived and tested for UF. Therefore, in the paragraphs to come the models will be called UF-models, though there are no reasons to presume that the models are not valid for MF. For RO usually osmotic pressure models are used, sometimes in combination with a model that describes the deposition of solute particles at the membrane interface.

\section{A. The resistance models}

\section{A1. Filtration models}

The total resistance $R_{b l}$ as needed in Eqn. 3 is calculated from the thickness of the boundary layer $\delta$ and the specific resistance $r_{b l}$. In general the total resistance will be

$R_{b l}=\int_{0}^{\delta} r_{b l} \mathrm{~d} x$

which is equal to $r_{b l} \cdot \delta$ when the cake-filtration theory is used.

The specific resistance is given by the Kozeny-Carman relationship

$r_{b l}=180 \cdot \frac{(1-\varepsilon)^{2}}{\left[\left(d_{s}\right)^{2} \varepsilon^{3}\right]}$

where $\varepsilon$ is the porosity of the concentrated layer and $d_{s}$ is the 'diameter' of the solute particle. In case a solid deposit has been formed and its mass can be determined, the thickness $\delta$ of the concentrated layer is equal to 
$\delta=\frac{m_{s}}{\left\{\rho_{s}(1-\varepsilon) A\right\}}$

where $m_{s}$ is the mass of the deposit or concentrated layer, $\rho_{s}$ is the density of the solute and $A$ is the membrane area. The influence of the applied pressure can be represented by

$r_{b l}=r_{b l, 0} \cdot \Delta P^{n}$

where $n$ is the compressibility factor. In the relationship

$\frac{r_{b l}}{C_{b l}}=\left(\frac{r_{b l}}{C_{b l}}\right)_{0} \cdot \Delta^{n}$

$n$ is found to be $0.5-0.7$ for solutes like BSA and silica [11,12].

The filtration model concept is used for all kinds of filtration: Howell and Velicangil [13] and Baker et al. [14] use it in a model for cross-flow UF. Fane [15] and Chudacek et al. [11] use the filtration model for describing stirred and unstirred dead-end filtration of several solutes.

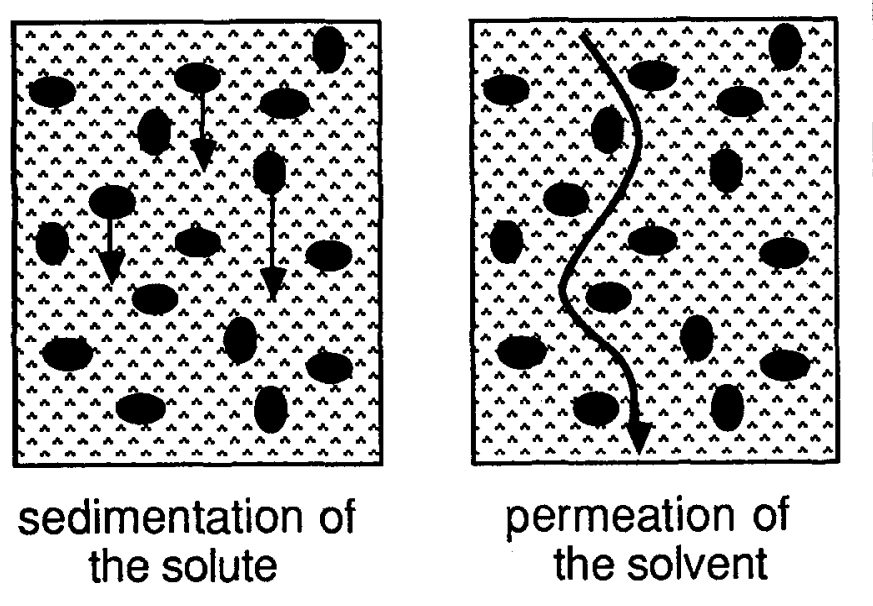

Fig. 7. The resemblance of sedimentation and permeability

A2. Boundary layer resistance models (BLR models)

The basic principle of boundary layer resistance models is the 
correspondence of the permeability of a concentrated layer for the solvent near a membrane interface and the permeability of a solute in a stagnant solution, as occurring during a sedimentation experiment (Fig. 7).

This relationship can be described by [16]

$$
p=\frac{\eta_{0} s(C)}{C\left(1-v_{1} / v_{0}\right)}
$$

where $p$ is the permeability of a concentrated layer of concentration $C, s(C)$ is the sedimentation coefficient at concentration $C$ and $v_{1}$ and $v_{0}$ are the partial specific volumes of the solute and the solvent respectively.

The specific resistance $r_{b l}$ is equal to the reciprocal permeability $p^{-1}$. Combined with Eqn. 14 this results in the total resistance, which is needed in Eqn. 3 to describe the flux. The sedimentation coefficient is usually strongly dependent on the concentration, which is described by

$s^{-1}=\left(s_{0}\right)^{-1} \cdot\left(1+K_{1} \cdot C+K_{2} \cdot C^{2}+K_{3} \cdot C^{3}\right)$

where $K_{1}, K_{2}$ and $K_{3}$ are constants. At the moment three versions of the BLR model exist: one for cross-flow UF [17] and two for unstirred dead-end UF $[18,19]$.

The cross-flow version of the BLR model uses Eqn. 13, 14, 19 and 20 to obtain

$$
R_{b l}=\frac{D}{J_{v}} \frac{\left(1-v_{1} / v_{0}\right)}{\eta_{0} s_{0}}\left[C_{m}-C_{b}+\frac{K_{1}}{2}\left(C_{m}^{2}-C_{b}^{2}\right)+\frac{K_{2}}{3}\left(C_{m}^{3}-C_{b}^{3}\right)+\frac{K_{3}}{4}\left(C_{m}^{4}-C_{b}^{4}\right)\right]
$$

Now the resistance can be calculated when the concentration at the membrane interface $C_{m}$ is known. Assuming $\Re_{\text {obs }}=1\left(C_{p}=0\right)$ changes Eqn. 12 into

$J_{v}=k \cdot \ln \frac{C_{m}}{C_{b}}$

from which $C_{m}$ can be calculated if $k$ is known.

Unfortunately, the mass transfer coefficient $k$ can not be easily calculated from process parameters. Many relationships have been proposed (by Deissler, Chilton-Colburn and others, see Gekaz [20] for a review), but none of these relationships can predict the exact mass transfer coefficient a priori. Corrections can be made for the concentration dependent parameters like the increased viscosity, the increased diffusion coefficient and/or the increased density of the 
solution [21]. In general it can be said that these corrections make the prediction of the mass transfer coefficient very complicated. The deduction of mass transfer correlations from actual ultrafiltration experiments is also difficult, because models have to be used to deduct the value of the mass transfer coefficient. While using concentration polarization models uncertainties occur because of logarithmic fitting of the experimental data [22].

The effect of an uncertainty in $k$ on the calculated total resistance may be large, because $C_{m}$ and therefore $R_{b l}$ are calculated from an exponential function:

$$
C_{m}=C_{b} \cdot \exp \left(J_{v} / k\right)
$$

A small error in the value of $k$ results in a large error in $C_{m}$ and an even larger error in the calculated value of the total resistance $R_{b b}$. Therefore Wijmans et al. [17] calculated the mass transfer coefficient and the concentration at the membrane interface by using the osmotic pressure model (section 3), after having proven that the BLR model and the osmotic pressure model are equivalent. An excellent agreement of the theoretical and experimental $R_{b t}$-values is the result, showing the validity of the BLR model (Fig. 8).

Nakao et al. [18] developed a BLR model for unstirred dead-end UF using the cake-filtration type of description. From the experiments they could calculate several properties of the concentrated layer, by using the experimental plot of $1 / J_{v}$ versus $V_{p} / A$ and the derivative of Eqn. 5 :

$$
\frac{\mathrm{d}\left(1 / J_{v}\right)}{\mathrm{d}\left(V_{p} / A\right)}=\left(\frac{\eta_{0} C_{b} \Re_{\mathrm{obs}}}{\Delta P}\right)\left(\frac{r_{b l}}{C_{b l}}\right)
$$

Knowing the values of $C_{b}, \eta_{0}, \Re_{\text {obs }}$ and $\Delta P$ the value of the so called flux decline index $r_{b l} / C_{b l}$ can be obtained readily from the experiments. The concentration $C_{b l}$ can be derived from $r_{b l} / C_{b l}$, via Eqn. 19 ,

$$
\frac{r_{b l}}{C_{b l}}=\left(\frac{\left(1-v_{1} / v_{0}\right)}{\eta_{0} s\left(C_{b l}\right)}\right)
$$

Unfortunately their model is not able to predict the fluxes or resistances directly, without doing some filtration experiments.

Van den Berg et al. [19] used the film model to describe the concentration profile near the membrane in combination with the basic BLR model equations. The flux during unstirred dead-end UF experiments was predicted by solving 
the differential equation (Eqn. 8) numerically and it showed an excellent agreement with the experimental data (Fig. 9). The only experimental data needed for the calculation is the sedimentation coefficient $s(C)$, as a function of concentration.

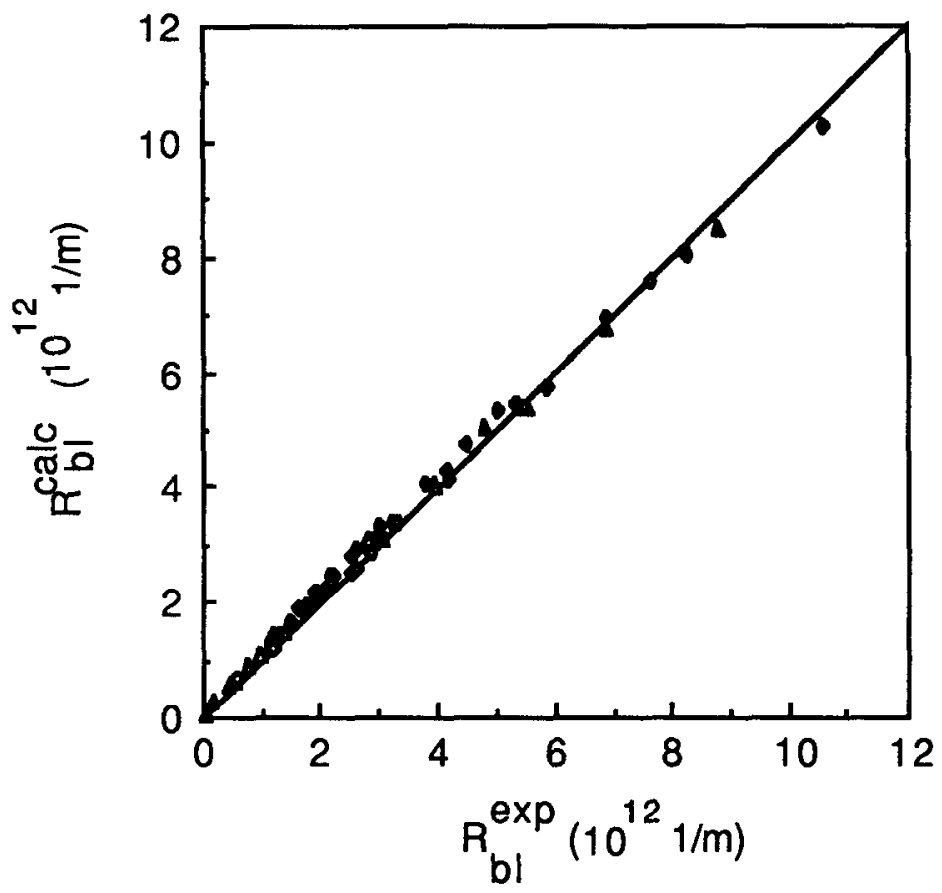

Fig. 8. Comparison of the experimental and calculated resistance of the boundary layer during cross-flow UF of Dextran T70.

The computer made it possible to study the influence of only one parameter, while in practice usually more than only the selected parameter changes because of mutual relationships. E.g. in Fig. 10 the calculated influence of the resistance of the membrane is shown to be of minor importance in comparison with the influence of the solute concentration.

The computed build-up of the concentration profile during a dead-end UF experiment is shown in Fig. 11.

It appears that the concentration at the membrane interface increases rapidly: $C_{m} \approx 260 \mathrm{~kg} / \mathrm{m}^{3}$ after 10 seconds, while the initial concentration was only 4.0 $\mathrm{kg} / \mathrm{m}^{3}$, and the thickness of the boundary layer after 10 seconds is $\delta \approx 20 \mu \mathrm{m}$. After 500 seconds these values are $350 \mathrm{~kg} / \mathrm{m}^{3}$ and $120 \mu \mathrm{m}$ respectively and at longer times the plateau value of approximately $405 \mathrm{~kg} / \mathrm{m}^{3}$ is reached and then 


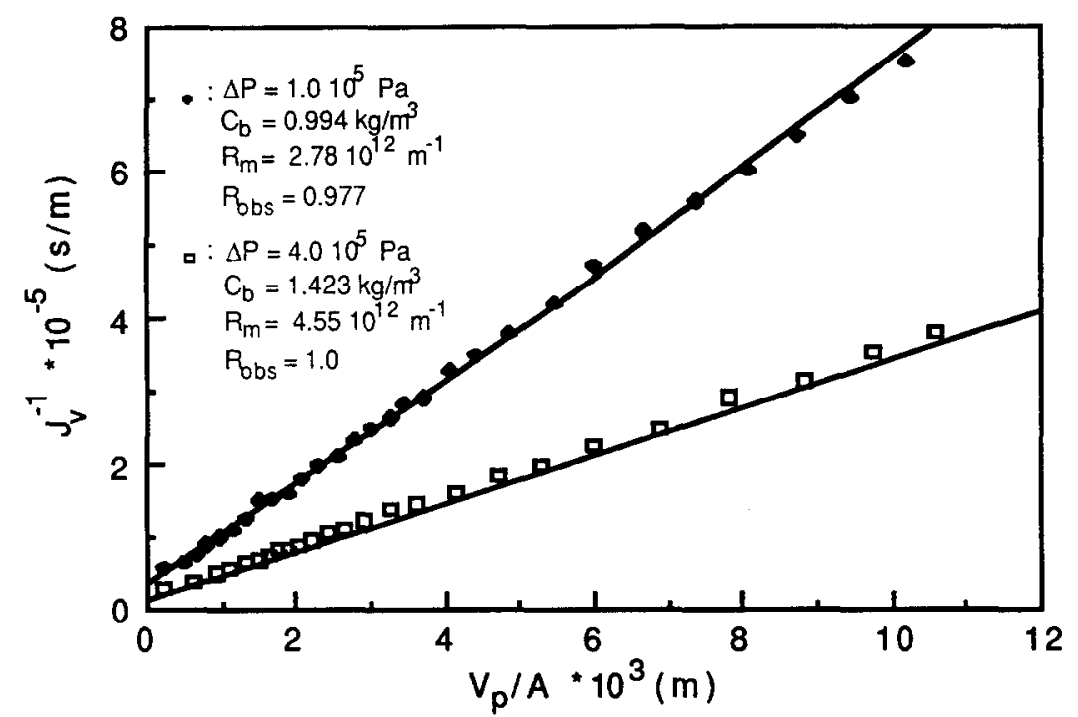

Fig. 9. A comparison between experimental data (data points) and a computer simulation (drawn lines) of UF-experiments with $\mathrm{BSA}$ at $\mathrm{pH}=7.4$ in various UF-situations.

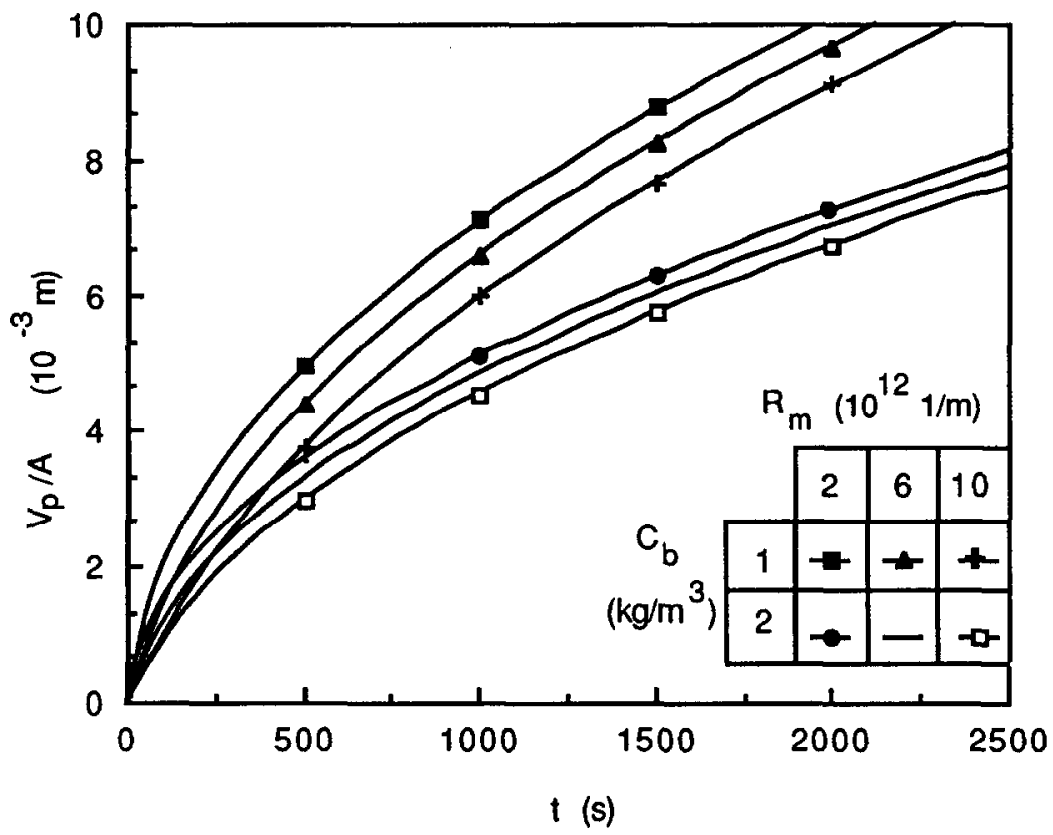

Fig. 10. The calculated influence of the resistance of a membrane on the flux behaviour. $\left(C_{b}=\right.$ 1 or $2 \mathrm{~kg} / \mathrm{m}^{3}, \Delta P=1.010^{5} \mathrm{~Pa}$ and $\Re_{o b s}=1.0$ ). 


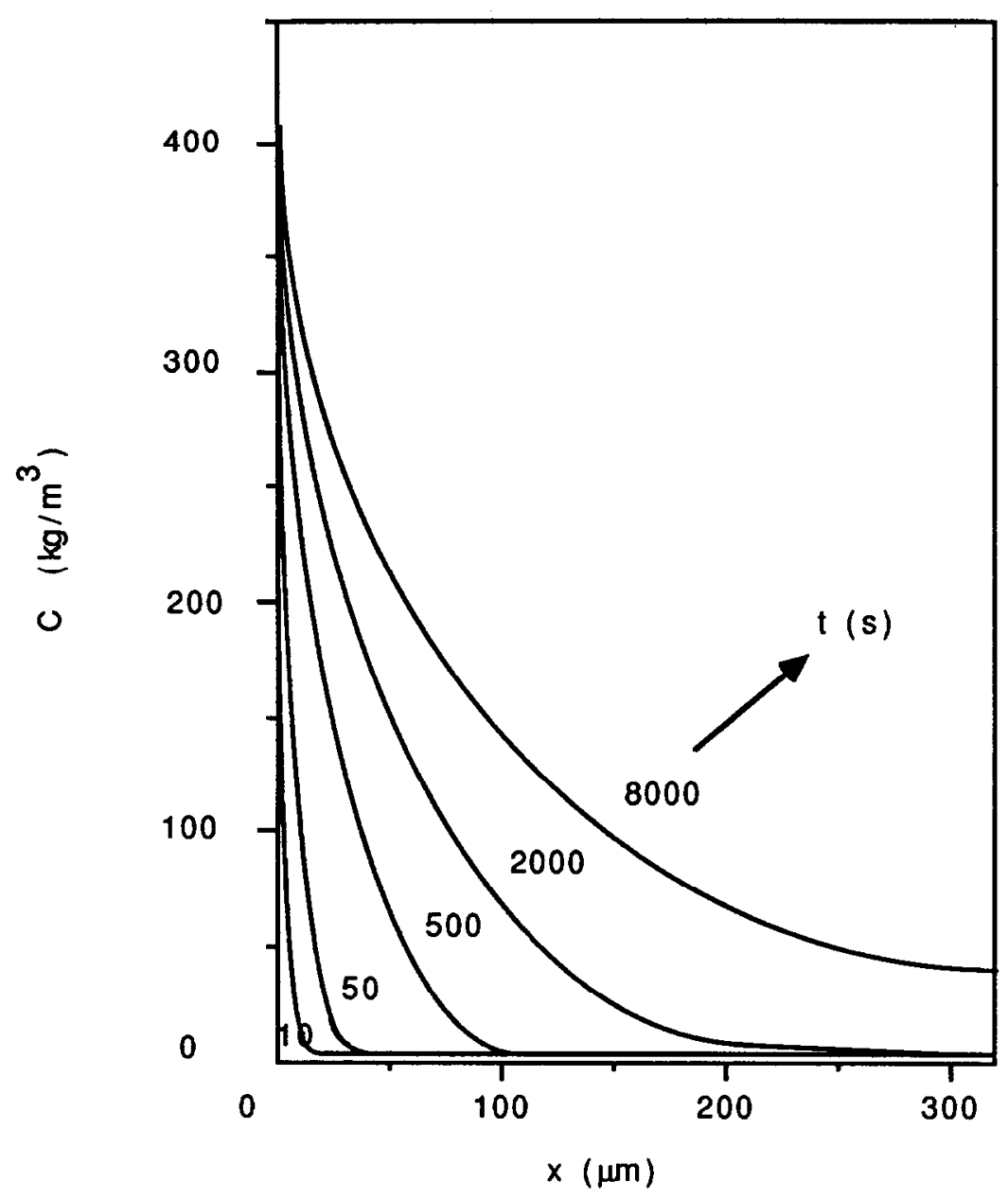

Fig. 11. Simulated concentration profiles near the membrane interface as a function of time for unstirred dead-end UF of BSA at $\mathrm{pH}=7.4, T=293 \mathrm{~K}$ and $I=0.125 \mathrm{~N}\left(\Delta P=1.10^{5} \mathrm{~Pa}, R_{m}=3.76\right.$ $10^{12} \mathrm{~m}^{-1}, \Re_{\text {obs }}=1.0, C_{b}=4.00 \mathrm{~kg} / \mathrm{m}^{3}$ )

only $\delta$ will increase. The study of the influence of the various parameters during unstirred dead-end UF is not disturbed by the unknown mass transfer coefficient, which is not relevant to this kind of filtration.

\section{B. The gel-polarization models}

The gel-polarization models all use the film theory to describe the concentration polarization phenomena (Eqn. 7). A characteristic of these models 
is the assumption that the concentration at the membrane interface can not exceed a fixed $C_{g}$-value. An increase of the applied pressure will then only result in an increased thickness of the gel layer but not in an increase in flux. The concentration profile can be thought to be as in Fig. 12, with both a concentration profile and a layer of constant concentration $C_{g}$. Gel-polarization models exist for unstirred dead-end UF, for stirred dead-end UF and for crossflow UF.

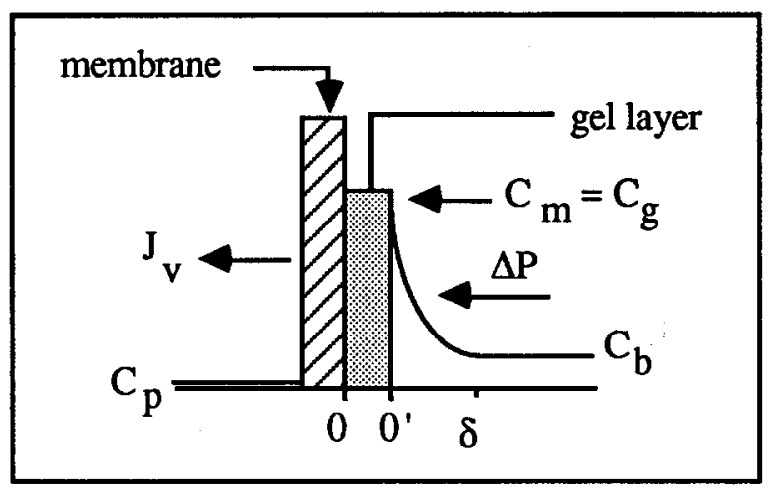

Fig. 12. Representation of the concentration profile near the membrane interface according to the gel-polarization theory.

The model for unstirred dead-end UF as proposed by Trettin and Doshi [23] includes an additional boundary condition viz. $C_{m}=C_{g}$ for all $t$. Furthermore they made the assumption of a constant diffusion coefficient and a fixed shape of the concentration profile outside the gel-layer of the form $C=C_{b}$ $+\left(C_{g}-C_{b}\right) \cdot(I-x / \delta)^{n}$ (note that $\left.\delta=\delta(t)\right)$. The number $\mathrm{n}$ is larger than zero and it is a function of $C_{g}, C_{b}$ and $C_{p}$. The resulting equation for the flux is:

$J_{v}=\left[\frac{C_{g}-C_{b}}{C_{g}-C_{p}}\right]\left[\frac{C_{g}-C_{p}}{C_{b}-C_{p}}\right]^{0.5}\left[\frac{n D}{2(n+1) t}\right]^{0.5}$

which can be simplified, for one filtration data-set, to

$J_{v}=$ constant $\cdot(D / t)^{0.5}$

showing the well-known $J_{v} \sim t^{0.5}$ or $V_{p} \sim t^{0.5}$ relationship for unstirred dead-end UF.

The models for stirred dead-end UF [24] and for cross-flow UF [24,25] use 
the equations of the film theory completed with one assumption: $C_{m}=C_{g}$ for all $t$. Eqn. 12 changes into

$$
J_{v}=\left(\frac{D}{\delta}\right) \ln \left\{\frac{C_{g}-C_{p}}{C_{b}-C_{p}}\right\}
$$

and with $D / \delta=k$ and $\Re_{\text {obs }}=1$ one obtains

$J_{v}=k \cdot \ln \frac{C_{g}}{C_{b}}$

As described in the paragraph on the BLR models, also for this model it appears to be very difficult to predict the mass transfer coefficient $k$ from process parameters.

Many experimental results do agree with this model, e.g. $J_{\nu} \neq f(\Delta P)$, $J_{v} \sim-\ln \left(C_{b}\right)$ and $J_{v}=f(k)$. However, the model can not explain why the limiting concentration of one chosen solute at $J_{v} \neq 0$, which is assumed to define $C=C_{g}$, changes when that solute is filtered in two different filtration-cells [25].

\section{The osmotic pressure models}

In general a macromolecular solution has a very small osmotic pressure in comparison to an equal weight-percentage low molecular salt solution. As shown in the previous paragraphs, during the filtration of the macromolecular solution a large concentration build-up can be realized. The osmotic pressure of very concentrated solutions can increase to enormous values, as shown by several measurements and/or calculations [17,26-29] The osmotic pressure of a single solute can be calculated indeed, up to very high concentrations, using several characteristics of the solute. The equation of van ' $t$ Hoff for ideal, diluted solutions

$$
\pi=R \cdot T \cdot C / M
$$

where $R$ is the gas constant, $T$ the absolute temperature and $M$ the molecular weight. This equation can not be used and should be extended to the equation for the osmotic pressure of non-ideal solutions:

$$
\pi=(R T / M)\left(C+B_{2} C^{2}+B_{3} C^{3}+\ldots . .\right)
$$


in which the virial coefficients $B_{2}$ and $B_{3}$ can be calculated as a function of parameters such as excluded volume, hydration and Donnan effects [27,29].

A few examples of osmotic pressures, at $400 \mathrm{~kg} / \mathrm{m}^{3}$ (which is a normal wall concentration, see previous section on the BLR models):
$\pi$ (Dextrans)
$\approx 710 \mathrm{kPa}$
[17],
$\pi$ (protein BSA at $\mathrm{pH} 5.4$ )
$\approx 130 \mathrm{kPa}$
[27],
$\pi$ (protein B-lactoglobulin at $\mathrm{pH} 6.6) \approx 260 \mathrm{kPa}$
$\pi$ (whey proteins)
$\approx 650 \mathrm{kPa}$
[29] and

Kedem and Katchalsky used non-equilibrium thermodynamics to derive expressions for the solvent flux and the solute flux respectively [30]:

$J_{v}=L_{p}(\Delta P-\sigma \Delta \pi)=\frac{(\Delta P-\sigma \Delta \pi)}{\eta_{0} R_{m}}$

$J_{s}=P\left(C_{m}-C_{p}\right)+(1-\sigma) J_{v}\langle C\rangle$

where $L_{p}$ is the pure water permeability, $\sigma$ is the reflection coefficient, $\Delta \pi=$ $\pi\left(C_{m}\right)-\pi\left(C_{p}\right), P$ is the membrane permeability for the solute and $\langle C\rangle$ is the concentration averaged over both sides of the membrane, for which usually the logarithmic mean is used. Spiegler and Kedem [31] derived for the intrinsic retention $R$

$R=1-\left(C_{p} / C_{m}\right)=\sigma(1-F) /(1-\sigma F)$

where $F$ is

$F=\exp \left[-(1-\sigma) \cdot J_{v} / P\right]$

When $C_{p}=0$, so $\Re_{\mathrm{obs}}=R=\sigma=1$, Eqn. 32 changes into

$J_{v}=(\Delta P-\Delta \pi) /\left(\eta_{0} \cdot R_{m}\right)$

An osmotic pressure model for unstirred dead-end filtration was described by Vilker et al. [32]. They used the film theory (i.e. Eqn. 7-11) in combination with Eqn. 32 to obtain an expression for the flux, in case of a highly rejecting membrane:

$J_{v}=(D / t)^{0.5} \cdot f\left(C^{*}, C_{b}\right)$

where $C^{*}$ is the concentration for which $\Delta P-\sigma \Delta \pi=0$.

For one set of conditions the function of $C^{*}$ and $C_{b}$ is constant, which turns Eqn. 37 into 
$J_{v}=$ constant $\cdot(D / t)^{0.5}$

Like all other models for unstirred dead-end filtration this model also predicts a $J_{v} \sim t 0.5$ relationship.

The osmotic pressure models for stirred dead-end filtration and cross-flow filtration are essentially the same. Jonsson [28] describes stirred UF and Goldsmith [26] describes cross-flow filtration, both using the film theory (resulting in Eqn. 22) and the flux equation including the osmotic pressure (Eqn. 32). From these equations and the dependence of the osmotic pressure on concentration from experimental data the mass transfer coefficient can be calculated. Jonsson [28] finds a reasonable, but certainly not $100 \%$, agreement with theoretical mass transfer data.

It is shown from the experimental data, represented in a semi-logarithmic plot of $J_{v}$ versus $\ln \left(C_{b}\right)$, that extrapolation to $J_{v}=0$ can result in a $C_{m}$-value, corresponding to an osmotic pressure which is equal to the applied pressure $\Delta P$. So instead of a 'fixed' gel concentration, as used in the gel-polarization models, a variable concentration $C_{m}=f(\Delta P)$ is assumed to be reached at the membrane interface.

Wijmans et al. [33] showed mathematically that the osmotic pressure model has many characteristics in common with the gel-polarization model. They used

$J_{v}=\frac{(\Delta P-\Delta \pi)}{\eta_{0} R_{m}}$

and a relationship for the osmotic pressure as a function of concentration of the form

$\Delta \pi=a \cdot C^{n}$

where $a$ is a constant and $n$ an exponent larger than 1, together with Eqn. 13 and $\Delta \pi=f\left(C_{m}\right)$ this results in

$J_{v}=\frac{\left[\Delta P-a \cdot\left(C_{b}\right)^{n} \cdot \exp \left(n J_{v} / k\right)\right]}{\eta_{0} R_{m}}$

From this equation it is clear that the flux will not increase linearly with the applied pressure. Furthermore, other filtration characteristics can be derived also from the derivative $\partial J_{v} / \partial \Delta P$ 
$\frac{\partial J_{v}}{\partial \Delta P}=\left[\eta_{0} \cdot R_{m}+(n / k) \cdot \Delta \pi\right]^{-1}=\frac{\left[1+\left(\Delta \pi \cdot n /\left(\eta_{0} \cdot R_{m} \cdot k\right)\right)\right]^{-1}}{\eta_{0} \cdot R_{m}}$

For high effective values of $\Delta \pi$ the derivative $\partial J_{\downarrow} / \partial \Delta P$ will be almost zero (pressure independent filtration), while for $\Delta \pi \approx 0$ the term $\partial J_{v} / \partial \Delta P$ will be near $1 / \eta_{0} \cdot R_{m}$ (as it is for pure water filtration). The term $\Delta \pi \cdot n / \eta_{0} \cdot R_{m} \cdot k$ was shown to be the ratio of the resistances caused by the osmotic pressure and the membrane itself. At high values of this ratio the solution is supposed to be very polarized at the membrane interface. Another derivative, $\partial J_{v} / \partial \ln C_{b}$, is equal to

$\frac{\partial J_{\nu}}{\partial \ln C_{b}}=-\left\{1 / k+1 /\left[n\left(\frac{\Delta P}{\eta_{0} \cdot R_{m}-J_{\nu}}\right)\right]\right\}^{-1}=-k\left[1+\frac{\left(\eta_{0} \cdot R_{m} \cdot k\right)}{(\Delta \pi \cdot n)}\right]-1$

At high values of the ratio $\Delta \pi \cdot n / \eta_{0} \cdot R_{m} \cdot k$ the term $\partial J_{\downarrow} / \partial J \ln C_{b}$ almost will be equal to $-k$, which is also the predicted slope in plots of $J_{v}$ versus $\ln C_{b}$ in the gel-polarization model.

The factors that can lead to a high $\Delta \pi \cdot n / \eta_{0} \cdot R_{m} \cdot k$ ratio (large flux decline by osmotic effects) were summarized as follows:

1 high permeate fluxes, obtained by a large applied pressure or a small $R_{m-}$ value,

2 high bulk concentrations,

3 low mass transfer coefficients: a small diffusion coefficient of the solute (a macromolecular solute) and/or a low degree of mechanical mixing near the membrane interface,

4 a high exponent $n$, i.e. a macromolecular solute,

5 a high value of the constant $a$, i.e. a low molecular weight of the solute, which is the opposite of factors 3 and 4.

Thus the desired high degree of concentration of solutions, easily obtained at high fluxes, appears to be opposed by the same high flux and concentration.

\section{SOLUTE-SOLUTE INTERACTIONS}

As shown by Ingham et al. [34] and Fane [35], the presence of large solutes can influence the retention of smaller solutes. Changing the ionic strength or the $\mathrm{pH}$-value of the solution, while using the same amount of macro-solute, can change the flux, which was also shown by Fane [35]. It will be clear that these changes can influence the properties of the solute and so the flux behaviour, indicating the importance of interactions between the micro- and macro-solutes 
in a solution. An example of macro-/macro-solute interaction can also be found: an increase in concentration of the protein $\beta$-lactoglobulin will result in an increasing retention because of self-association [29].

\section{The influence of different solutes}

In addition to the phenomena mentioned above Van den Berg et al.[36] studied the flux decline behaviour of some charged proteins and of binary mixtures of charged solutes during unstirred dead-end ultrafiltration. The mixtures consisted of the proteins BSA, $\alpha$-lactalbumin and/or lysozyme. Of special interest were $\alpha$-lactalbumin and lysozyme because these proteins are physico-chemically identical, except for the iso-electric point (I.E.P.) and therefore the net charge at the conditions used, as can be seen in Table I [36].

The consequence of the identical properties is that the filtration behaviour of the proteins separately has to be identical because the values of $s(C), D(C)$ and $v_{1}$ are the same and those are the only parameters necessary to describe the deadend filtration phenomena with the boundary layer resistance model. The boundary layer resistance model uses the sedimentation coefficient as a function of concentration. In Fig. 13 the dependence of $s$ on the concentration is represented [36].

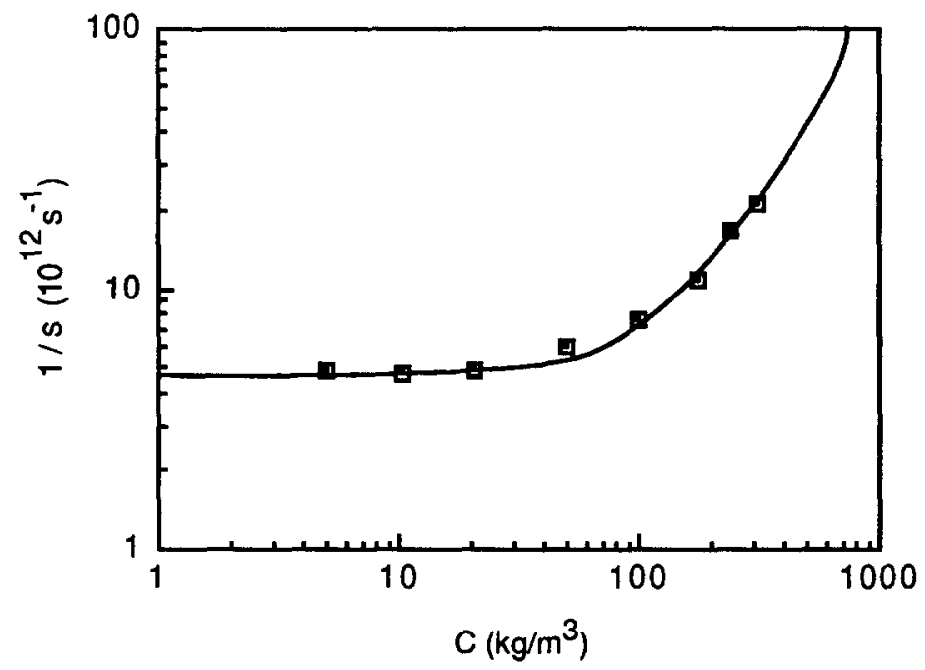

Fig. 13. The measured reciprocal sedimentation coefficient of lysozyme as a function of concentration ( $\mathrm{pH}=7.4, I=0.125 \mathrm{~N}$ and $T=20^{\circ} \mathrm{C}$ ). 
Curve fitting of these data resulted in:

$$
\begin{aligned}
1 / s= & \left(1+1.06710^{-3} * C+5.53710^{-5 *} C^{2}-1.34110^{-7 *} C^{3}+1.85610^{-10 *} C^{4}\right) \\
& /\left(2.04210^{-13}\right)
\end{aligned}
$$

In Fig. 14 the so-called flux decline index $r_{b l} / C_{b l}$ (see Eqn. 24) is indeed shown to be equal for these proteins.

The plateau values are about 3.9 and $10.8 * 1015 \mathrm{~m} / \mathrm{kg}$ respectively for the applied pressures 1.0 and $4.0105 \mathrm{~Pa}$. For BSA values of 3.8 and $10.5 * 1015$ $\mathrm{m} / \mathrm{kg}$ respectively were found at the pressures mentioned [19]. As these values do not differ very much for these three proteins, the question arises whether the flux decline index could perhaps be about the same for all solutes at a given pressure. In Table II a number of flux decline indices is given for different kinds of solutes at applied pressures $\Delta P=1.0$ and $4.0 * 10^{5} \mathrm{~Pa}$ (most data were obtained from reading data-points in plots which makes them approximate values).

\section{TABLE I}

Physico-chemical properties of the proteins lysozyme, $\alpha$-lactalbumin and BSA (data are at $\mathrm{pH}=7.4, T=20^{\circ} \mathrm{C}$ and $I=0.125 \mathrm{~N}$, or closest data available)

\begin{tabular}{|l|c|c|c|}
\hline & lysozyme & $\alpha$-lactalbumin & $B S A$ \\
\hline $\begin{array}{l}M_{w} \\
\text { (Dalton) }\end{array}$ & $\begin{array}{l}14,200 \\
14,100\end{array}$ & 14,400 & 69,000 \\
\hline I.E.P. & 11.0 & 5.1 & 4.7 \\
\hline $\begin{array}{l}\text { net charge } \\
\text { at pH }=7.4\end{array}$ & +7 & -7 & -22 \\
\hline $\begin{array}{l}D_{c=0} \\
\left(10^{-11} \mathrm{~m}^{2} / \mathrm{s}\right)\end{array}$ & 10.7 & 10.6 & 5.9 \\
\hline $\begin{array}{l}\mathrm{s}_{\mathrm{c}=0} \\
\left(10^{-13} \mathrm{~s}\right)\end{array}$ & 1.86 & 1.83 & 4.41 \\
\hline $\begin{array}{l}\mathrm{v}_{1} \\
\left(10^{-4} \mathrm{~m}^{3} \mathrm{~kg}\right)\end{array}$ & 7.26 & 7.35 & 7.34 \\
\hline$r_{s}(\mathrm{~nm})$ & 2.00 & 2.02 & 3.64 \\
\hline
\end{tabular}


Dejmek [37] found almost identical values for the specific 'gel' resistance $(\mathrm{m})$ of the proteins hemoglobin and $\beta$-lactoglobulin $\left(r_{b l} / C_{b l}=(m) / \eta_{0}\right)$. Nakao et al. [18] calculated much higher values for the flux decline index of the solutes Dextran T500 and PEG 600. On the other hand, data by McDonogh et al. [38] for silica colloids with varying zeta potentials show much lower values.

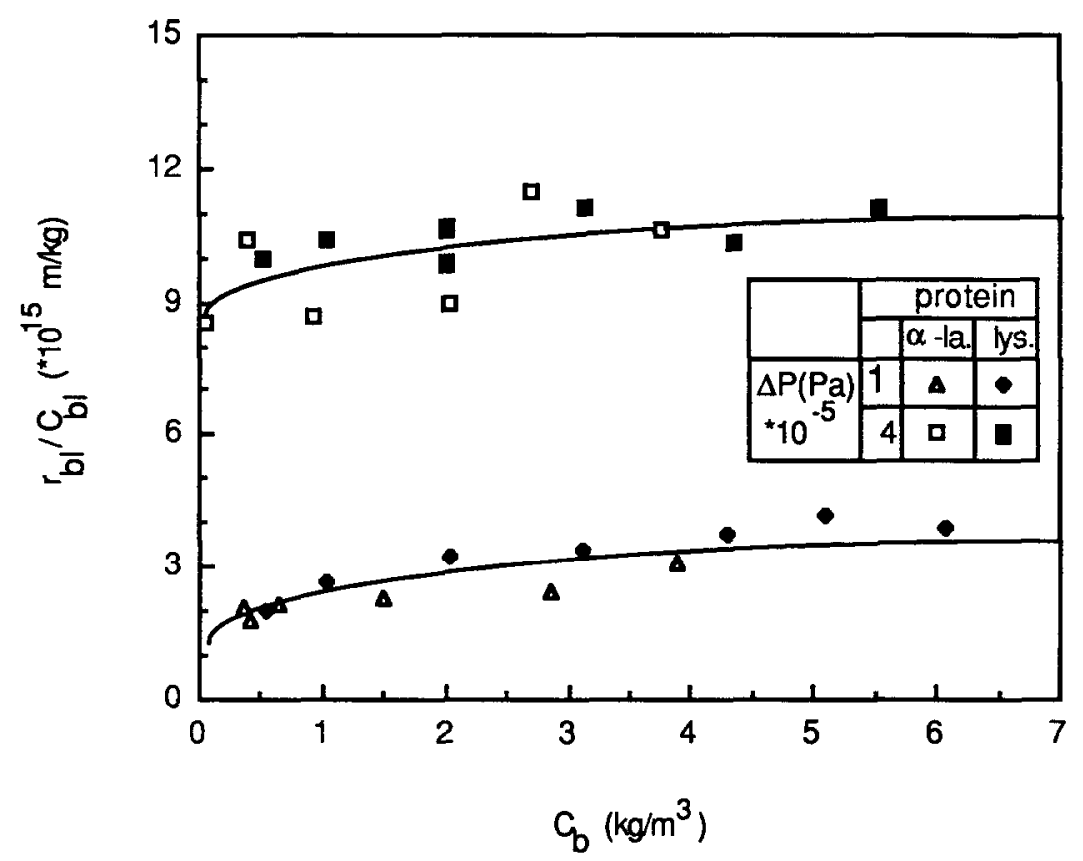

Fig. 14. The flux decline index $r_{b l} / C_{b l}$ as a function of concentration in the bulk for the proteins $\alpha$-lactalbumin and lysozyme. $\Delta P=1.0$ or $4.010^{5} \mathrm{~Pa}$.

The almost identical values for the proteins and the different values for the other solutes seem to lead to the conclusion that the permeability of a concentrated boundary layer depends on the compactness and type of packing of these solutes. A concentrated layer of the rather compact and impermeable particles of protein molecules is more permeable than a layer of highly swollen, entangled polymers (Dextrans and PEG), but less permeable than a layer of very compact but rather loosely packed silica colloids. The observation by McDonogh et al. that a higher zeta potential (more open structure) decreases the specific resistance of colloids agrees with this conclusion. In the case of Dextran T70 and PEG 600 (above the overlap concentration which is about 5\%) the transport of the solvent water probably occurs through the molecular coils (intramolecular) while the transport occurs around the particles (intermolecular) in the case of proteins and colloids [16]. 


\section{TABLE II}

The flux decline index of several solutes at applied pressures $\Delta P=1.0$ and $4.010^{5} \mathrm{~Pa}$, most data taken from literature

\begin{tabular}{|l|c|c|c|}
\hline solute & $\Delta \mathrm{P}\left(10^{5} \mathrm{~Pa}\right)$ & $\frac{\mathrm{C}_{\mathrm{bl}}}{\mathrm{C}_{\mathrm{bl}}}\left(10^{15} \mathrm{~m} / \mathrm{kg}\right)$ & Reference \\
\hline lysozyme or & 1 & 3.9 & {$[36]$} \\
$\alpha$ - lactalbumin & 4 & 10.8 & \\
\hline BSA & 1 & 3.8 & {$[19]$} \\
\hline hemoglobin & 1 & 10.5 & {$[37]$} \\
\hline B- lactoglobulin & 1 & 3.8 & {$[37]$} \\
\hline Dextran T500 & 4 & 11.5 & {$[18]$} \\
\hline PEG 600 & 4 & 3.1 & {$[18]$} \\
\hline silica colloids & 1 & 13.5 & {$[38]$} \\
\hline
\end{tabular}

\section{The influence of solute-solute interactions}

A mixture of the proteins $\alpha$-lactalbumin (net charge $=-7$ ) and lysozyme (net charge $=+7$ ), or a mixture of BSA (net charge $=-22$ ) with one of these proteins, is interesting to study the interactions of proteins during dead-end ultrafiltration. Except for charge interactions also an additional effect can be expected to occur when mixtures are ultrafiltered: a difference in packing during the solute build-up near the membrane interface.

When the Stokes radius $(3.64 \mathrm{~nm}$ for BSA and $2.02 \mathrm{~nm}$ for $\alpha$-lactalbumin and lysozyme) is taken as a reference the diameter-ratio is 0.55 when BSA is in the mixture and is 1.00 otherwise. From literature [e.g. 39] it is known that mixing particles of different size will then increase the overall packing density and it therefore will enhance the resistance to permeation of solvent. The extent of this effect depends on the particle diameter ratio and the way of packing.

In Fig. 15 the experimental flux decline indices are given as a function of the 
molar fraction BSA present in mixtures with either lysozyme or $\alpha$-lactalbumin. The data at $x=0$ and $x=1$ are the plateau values for the flux decline indices of the single proteins.

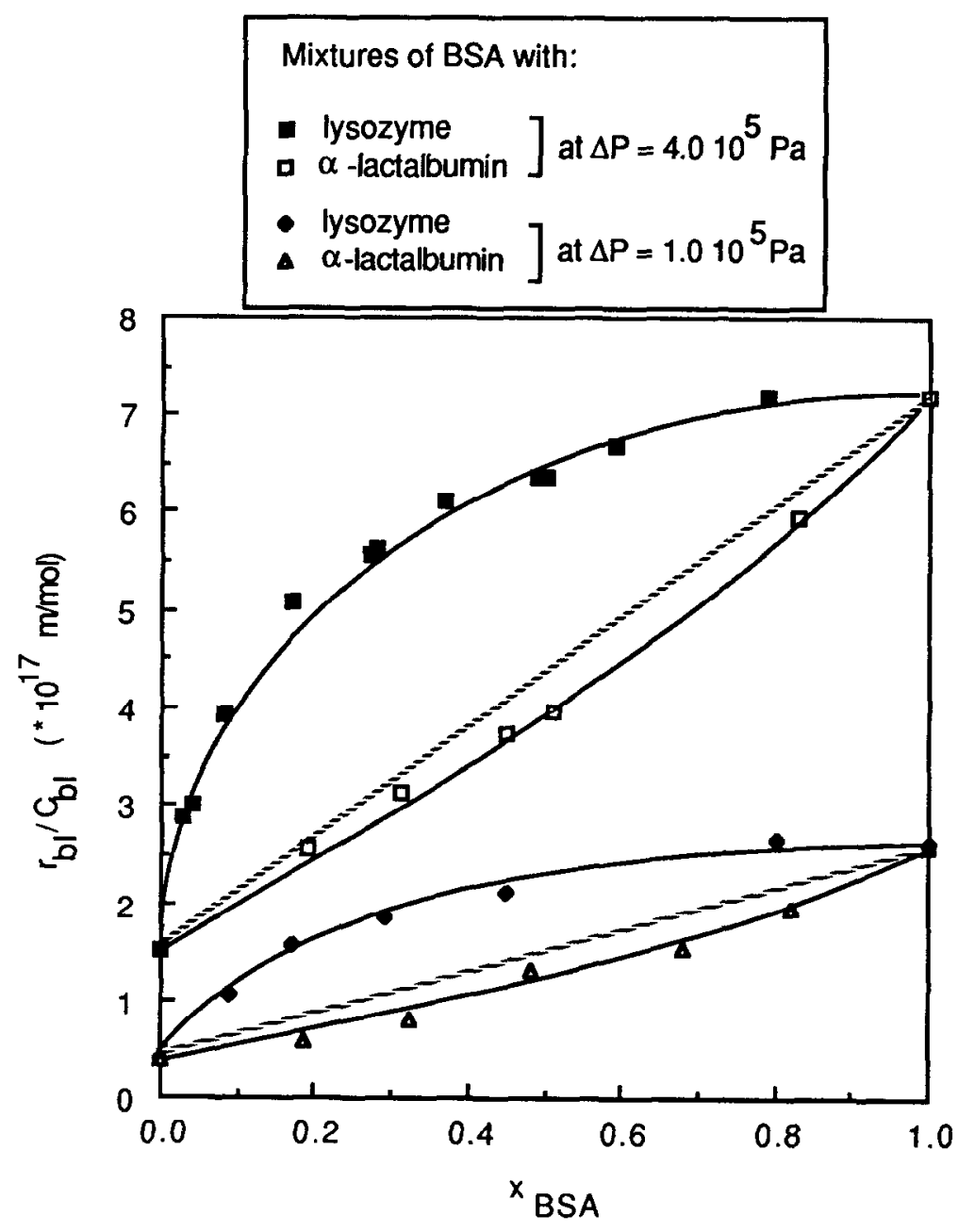

Fig. 15. The flux decline index $r_{b l} / C_{b l}$ (on molar basis) for mixtures of BSA with $\alpha$-lactalbumin or lysozyme, as a function of the molar fraction BSA in the solution. $\Delta P=1.0$ and $4.010^{5} \mathrm{~Pa}, T=20^{\circ} \mathrm{C}, \mathrm{pH}=7.4$ and $I=0.125 \mathrm{~N}$. The concentration in the bulk solution was between 1 and $5 \mathrm{~kg} / \mathrm{m}^{3}$.

For the two pressures studied the values for the flux decline index of a mixture of BSA and $\alpha$-lactalbumin (both negatively charged) show slightly smaller values than a linear relation between the flux decline indices of both 
proteins. This means that the BSA and $\alpha$-lactalbumin molecules have built up a concentrated layer during filtration with a slightly decreased flux decline index in comparison with two equally interacting proteins in the mixture. The repulsion between these different molecules is almost equal to the repulsion between the proteins of only one kind of protein. The deviation to a more loosely packed boundary layer could perhaps be due to the non-spherical dimensions of the BSA molecule.

The data on the mixtures of BSA and lysozyme show a quite different flux behaviour. The flux decline index is larger than the linear relationship between the indices of the single protein solutions indicates. The index can reach values up to twice the predicted value (i.e. for $x_{B S A} \approx 0.1$ to 0.2 ). The origin of the larger

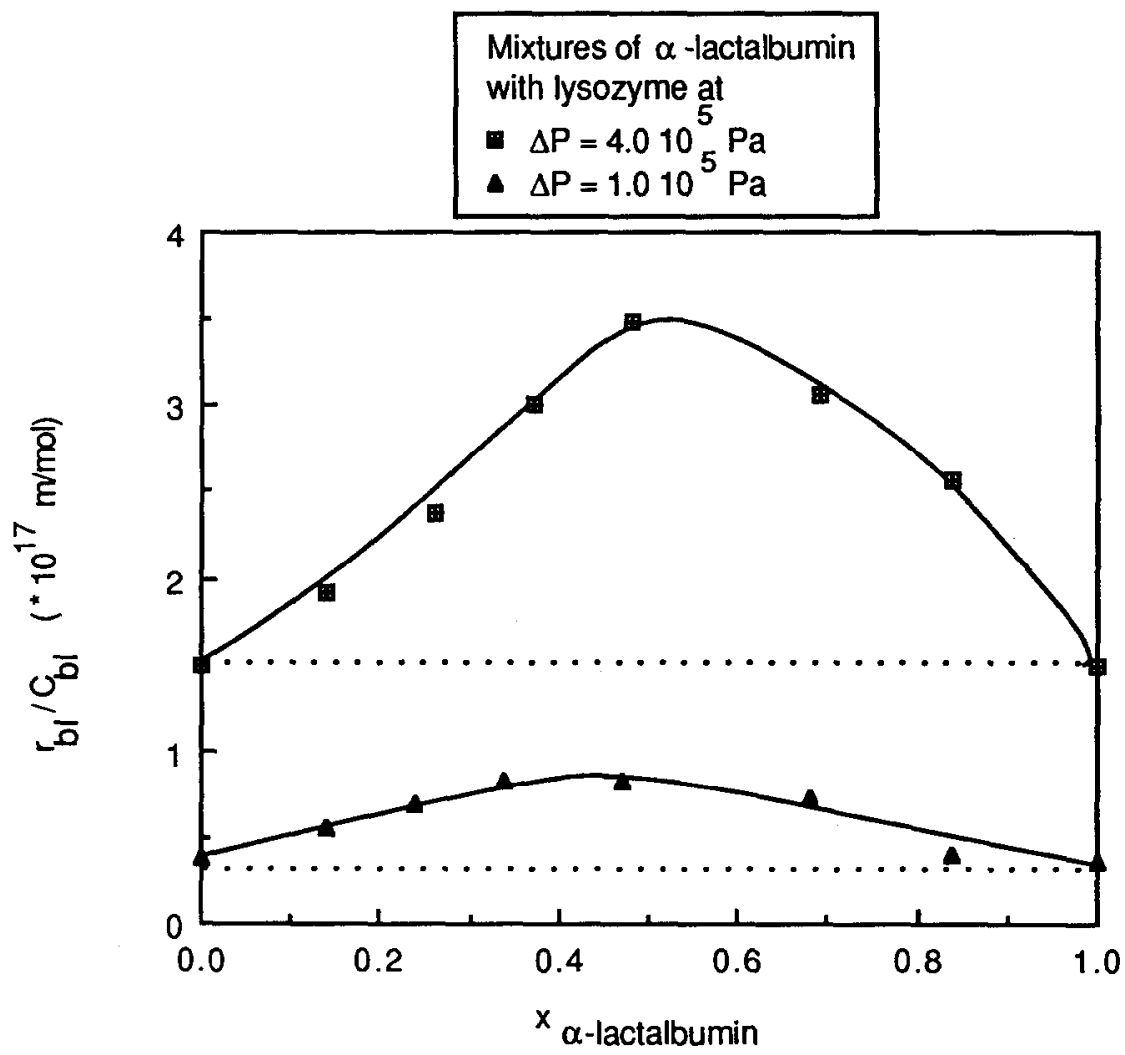

Fig. 16. The flux decline index $r_{b l} / C_{b l}$ (on molar basis) for mixtures of $\alpha$-lactalbumin with lysozyme, as a function of the molar fraction $\alpha$-lactalbumin in the solution. $\Delta P=1.0$ and 4.0 $10^{5} \mathrm{~Pa}, \mathrm{pH}=7.4, T=20^{\circ} \mathrm{C}$ and $I=0.125 \mathrm{~N}$. 
resistance than that predicted for non-interacting particles may be found in a tighter packing of the concentrated layer. This is possible because of the oppositely charged particles.

In Fig. 16 the results for the experiments using mixtures of the equally sized but oppositely charged $\alpha$-lactalbumin and lysozyme are shown.

For these mixtures the flux decline index is also considerably larger than the values for the single protein solutions and seems to indicate a maximum near $\mathbf{x}_{\alpha \text {-lactalbumin }}=0.5$. Here the flux decline index appears to be about 2.3 times as large as in the case of single protein solutions. The packing of the positively and negatively charged protein molecules will again be much more dense than in the case of the single protein solutions. Except for the sign of the charge these molecules are totally identical as to the physico-chemical properties and the flux behaviour (Table I and Fig. 14). Hence the specific resistance or the flux decline index could be expected to be totally constant if the attraction were not present.

The effect of oppositely charged but further identical molecules in a network can only be an enhanced packing density and an increasing resistance, probably with a maximum in resistance at $x_{\alpha \text {-lactalbumin }}=0.5$ because of the numerically equal charge for lysozyme and $\alpha$-lactalbumin respectively and identical dimensions for these proteins. Looking only at mutual charge compensation for the effect on packing density (and not at the influence of particle dimensions) the maximum relative increase in resistance for the case of mixing lysozyme and $B S A$ could be expected at $x_{B S A}=0.25$. This is not too far off from the actual situation found in Fig. 15.

\section{IMPROVEMENT OF FLUXES}

As indicated in the paragraphs above, flux enhancement is possible by destroying the concentrated layer near the membrane, but this is not the only way to improve the flux. Also prevention of fouling phenomena might work for flux improvement. An extended review of methods to diminish the flux decline is given by Matthiasson and Sivik [40].

The methods to improve the flux can be generally divided into 1) adapting the operating conditions in the existing equipment, 2) altering the conditions in the solution, 3) using a different or pretreated membrane, 4) taking additional measures to prevent or decrease the flux decline.

1. Equipment related methods: unstirred dead-end filtration is always less favourable for the flux-behaviour than stirred dead-end filtration or cross-flow filtration, which both can be characterized by a mass transfer coefficient. Directly from theoretical considerations it can be seen that a larger mass transfer coefficient will increase the flux. As the mass transfer coefficient is a function of 
both solute and equipment related parameters the improvement of the value of $\mathrm{k}$ can be realized e.g. by increasing the cross-flow velocity, changing the flow channel or decreasing the viscosity, which is possible by increasing the temperature.

2. Solution related methods: when scaling is a problem scaling-inhibitors can be added, ion exchange can reduce the concentration of salts or the $\mathrm{pH}$ can be altered. Changing the value of the $\mathrm{pH}$ can also result in a decreased osmotic pressure and can postpone gelation by an increase of the gel concentration. Sometimes a pH change is counteractive on the different parameters. Enzymatic hydrolysis of the solute in the boundary layer can also result in an increased flux [41].

3. Membrane related methods: a chemical treatment can alter the surface of the membrane to make it less hydrophobic (less adsorption). Attaching hydrophilic chains on a hydrophobic membrane is also known to increase the flux during protein UF [42,43]. In situ removal of the concentrated layer is possible by immobilizing hydrolytic enzymes on the membrane surface [13]. Related to increasing the mass transfer coefficient is the use of corrugated membranes [44].

4. Additional measures: Prefiltration of a solution with serious fouling capacities can make a process much more economic. The use of special rotating equipment or membranes can increase the mass transfer coefficient [45]. Also increasing the mass transfer coefficient and the flux results from pulsing the feed solution flow [43], the use of a counter-current cascade [46] or the use of static mixers [47]. Recently a few methods have been described to improve the flux by the use of relatively small electrical current pulses $[48,49]$. When a deposit has been formed on the membrane surface backflushing a small amount of the permeate can improve the total efficiency [50,51]. Finally, membranes which have been fouled can be cleaned chemically or mechanically.

\section{CONCLUSIONS}

The flux decline during membrane filtration processes can be caused by many phenomena, mainly subdivided into fouling phenomena and concentration polarization. The concentration polarization phenomenon, which is always present when a membrane separation occurs, can be described by the film theory or a cake-filtration type of description. The effects of the increased concentration at the membrane interface has been described by several models. These concentration polarization models can be subdivided in resistance models (filtration and boundary layer resistance models), gel-polarization models and 
osmotic pressure models. Many of these models can describe the filtration phenomena (e.g. the $J_{v} \sim t^{-0.5}$ relationship for unstirred dead-end filtration). A limiting factor however is the difficulty to predict the mass transfer coefficient which is needed when stirred dead-end or cross-flow filtration is used.

Different groups of solutes exist, e.g. proteins or colloids, each with a different flux declining behaviour. The flux behaviour of mixtures of proteins during unstirred dead-end ultrafiltration can be very different from the behaviour of the single proteins. Both larger and about equal flux decline indices can be determined for solutions with mixtures of solutes, compared to the single solute solutions. The net charge of the molecules can give essential information of the kind of interactions which will lead to a different fouling behaviour.

On the basis of an increase of the mass transfer coefficient or a pretreatment of the feed solution, to give a smaller fouling potential, many methods are used in practice to improve the flux.

\section{REFERENCES}

1 E. Matthiasson, The role of macromolecular adsorption in fouling of ultrafiltration membranes, J. Membrane Sci., 16 (1983) 23-36.

2 L.J. Zeman, Adsorption effects in rejection of macromolecules by ultrafiltration membranes, J. Membrane Sci., 15 (1983) 213-230.

3 P. Aimar, S. Baklouti and V. Sanchez, Membrane-solute interactions: influence on pure solvent transfer during ultrafiltration, J. Membrane Sci., 29 (1986) 207-224.

4 T.B. Choe, P. Masse, A. Verdier and M.J. Clifton, Membrane fouling in the ultrafiltration of polyelectrolyte solutions: polyacrylic acid and bovine serum albumin, J. Membrane Sci., 26 (1986) 17-30.

5 A. Suki, A.G. Fane and C.J.D. Fell, Modeling fouling mechanisms in protein ultrafiltration, J. Membrane Sci., 27 (1986) 181-193.

6 S. Yagisawa, A method for observing protein-protein interaction, J. Biochem. 77 (1975) 605-616.

7 A.G. Fane and C.J.D. Fell, A review of fouling and fouling control in ultrafiltration, Desalination, 62 (1987) 117-136.

8 P. Aimar, Membrane fouling, Summer School on Engineering Aspects of Membrane Processes, Aarhus, Denmark, 1986.

9 J.C. Schippers and J. Verdouw, The modified fouling index, a method of determining the fouling characteristics of water, Desalination, 32 (1980) 137-148.

10 H. Reihanian, C.R. Robertson and A.S. Michaels, Mechanisms of polarization and fouling of ultrafiltration membranes by proteins, J. Membrane Sci., 16 (1983) 237258.

11 M.W. Chudacek and A.G. Fane, The dynamics of polarisation in unstirred and stirred ultrafiltration, J. Membrane Sci., 21 (1984) 145-160.

12 P. Dejmek, Concentration polarization in UF, Ph.D.-thesis, Univ. of Lund, Sweden, 1975. 
13 J.A. Howell and O. Velicangil, Theoretical considerations of membrane fouling and its treatment with immobilized enzymes for protein ultrafiltration, in: A.R. Cooper (Ed.), Polymer Science and Technology, Vol. 13, Plenum Press, New York, NY, 1980, pp. 217-229.

14 R.J. Baker, A.G. Fane, C.J.D. Fell and B.H. Yoo, Factors affecting flux in crossflow filtration, Desalination, 53 (1985) 81-93.

15 A.G. Fane, Ultrafiltration of suspensions, J. Membrane Sci., 20 (1984) 249-259.

16 P.F. Mijnlieff and W.J.M. Jaspers, Solvent permeability of dissolved polymer material. Its direct determination from sedimentation measurements, Trans. Faraday Soc., 67 (1971) 1837-1854.

17 J.G. Wijmans, S. Nakao, J.W.A. van den Berg, F.R. Troelstra and C.A. Smolders, Hydrodynamic resistance of concentration polarization boundary layers in ultrafiltration, J. Membrane Sci., 22 (1985) 117-135.

18 S. Nakao, J.G. Wijmans and C.A. Smolders, Resistance to the permeate flux in unstirred ultrafiltration of dissolved macromolecular solutions, J.Membrane Sci., 26 (1986) 165-178.

19 G.B. van den Berg and C.A. Smolders, The boundary layer resistance model for unstirred ultrafiltration, A new approach, J. Membrane Sci., 40 (1989) 149-172.

20 V. Gekas and B. Hallström, Mass transfer in the membrane concentration polarization layer under turbulent cross flow. I. Critical literature review and adaption of existing Sherwood correlations to membrane operations. J. Membrane Sci., 30 (1987) 153-170.

21 A.G. Fane, C.J.D. Fell, D. Wiley and R. McDonogh, Concentration polarization, mass transfer and fluid dynamics in membrane systems, Summer School on Engineering Aspects of Membrane Processes, Aarhus, Denmark, 1986.

22 G.B. van den Berg, I.G. Rácz and C.A. Smolders, Mass transfer coefficients in crossflow ultrafiltration, accepted for publication in J. Membrane Sci.

23 D.R. Trettin and M.R. Doshi, Ultrafiltration in an unstirred batch cell, Ind. Eng. Chem. Fundam., 19 (1980) 189-194.

24 W.F. Blatt, A. Dravid, A.S. Michaels and L. Nelsen, Solute polarization and cake formation in membrane ultrafiltration: causes, consequences, and control techniques, in: J.E. Flinn (Ed.), Membrane Science and Technology, Plenum Press, 1970, pp. 47-97.

25 M.C. Porter, Concentration polarization with membrane ultrafiltration, Ind. Eng. Chem. Prod. Res. Dev. 11 (1972) 234-248.

26 R.L. Goldsmith, Macromolecular ultrafiltration with microporous membranes, Ind. Eng. Chem. Fundam., 10 (1971) 113-120.

27 V.L. Vilker, C.K. Colton and K.A. Smith, The osmotic pressure of concentrated protein solutions: effect of concentration and $\mathrm{pH}$ in saline solutions of bovine serum albumin, J. Coll. Interf. Sci., 79 (1981) 548-566.

28 G. Jonsson, Boundary layer phenomena during ultrafiltration of dextran and whey protein solutions, Desalination, 51 (1984) 61-77.

29 G.B. van den Berg, J.H. Hanemaaijer and C.A. Smolders, Ultrafiltration of protcin solutions; the role of protein association in rejection and osmotic pressure, $\mathrm{J}$. Membrane Sci., 31 (1987) 307-320.

30 O. Kedem and A. Katchalsky, Permeability of composite membranes, Trans. Farad. Soc., 59 (1963) 1941-1951.

31 K.S. Spiegler and O. Kedem, Thermodynamics of hyperfiltration (reverse osmosis) : criteria for efficient membranes, Desalination, 1 (1966) 311-326.

32 V.L. Vilker, C.K. Colton and K.A. Smith, Concentration polarization in protein 
ultrafiltration. Part II: Theoretical and experimental study of albumin ultrafiltered in an unstirred cell, AIChE Journal 27(4) (1981) 637-645.

33 J.G. Wijmans, S. Nakao and C.A. Smolders, Flux limitation in ultrafiltration: osmotic pressure model and gel layer model, J. Membrane Sci., 20 (1984) 115-124.

34 K.C. Ingham, T.F. Busby, Y. Sahlestrom and F. Castino, Separation of macromolecules by ultrafiltration: influence of protein adsorption, protein-protein interactions and concentration polarization, in: Ultrafiltration membranes and applications, A.R. Cooper (ed.), Plenum Press, New York, NY, 1980, p.141-158.

35 A.G. Fane, Factors affecting flux and rejection in ultrafiltration, J. Separ. Proc. Technol. 4(1) (1983) 15-23.

36 G.B. van den Berg and C.A. Smolders, Concentration polarization phenomena during dead-end ultrafiltration of protein mixtures. The influence of solute-solute interactions, accepted for publication in J. Membrane Sci.

37 P. Dejmek, Concentration polarization in ultrafiltration of macromolecules, Ph.D.Thesis, Lund Institute of Technology, Lund, Sweden, 1975.

38 R.M. McDonogh, C.J.D. Fell and A.G. Fane, Surface charge and permeability in the ultrafiltration of non-flocculating colloids, J. Membrane Sci. 21 (1984) 285-294.

39 J. Rodriguez, C.H. Allibert and J.M. Chaix, A computer method for random packing of spheres of unequal size, Powder Technology 47 (1986) 25-33.

40 E. Matthiasson and B. Sivik, Concentration polarization and fouling, Desalination, 35 (1980) 59-103.

41 J.L. Harris, Influence of gel layer theology on ultrafiltration flux of wheat starch effluent, J. Membrane Sci., 29 (1986) 97-109.

42 A.G. Fanc, C.J.D. Fell and K.J. Kim, The effect of surfactant pretrcatment on the ultrafiltration of proteins, Desalination, 53 (1985) 37-55.

43 H. Bauser, H. Chmiel, N. Stroh and E. Walitza, Interfacial effects with microfiltration membranes, J. Membrane Sci., 11 (1982) 321-332.

44 I.G. Rácz, J. Groot Wassink and R. Klaassen, Mass transfer, fluid flow and membrane properties in flat and corrugated plate hyperfiltration modules, Desalination, 60 (1986) 213-222.

45 M. Lopez-Leiva, Ph.D.-thesis, Univ. of Lund, Sweden, 1979.

46 R.A. Ward, E. Klein, P.A. Feldhoff and T.J. Turnham, Ultrafiltration: separation enhancement by counter-current cascading, J. Membrane Sci., 33 (1987) 97-111.

47 J. Hiddink, D. Kloosterboer and S. Bruin, Evaluation of static mixers as convection promoters in the ultrafiltration of dairy liquids, Desalination, 35 (1980) 149-167.

48 W.R. Bowen, R.S. Kingdon and H.A.M. Sabuni, Electrically enhanced separation processes-the basis of in-situ intermittent electrolytic membrane cleaning (IIEMC) and in-situ clectrolytic membranc restoration (IEMR), J. Membrane Sci., 40 (1989) 219229.

49 R.J. Wakeman and E.S. Tarleton, Membrane fouling in crossflow microfiltration by the use of electric fields, Chem. Eng. Sci., 42 (1987) 829-842.

50 B.R. Breslau, E.A. Agranat, A.J. Testa, S. Messinger and R.A. Cross, Hollow fiber ultrafiltration, Chem. Eng. Prog., 71 (1975) 74-80.

51 K.H. Kroner, H. Schütte, H. Hustedt and M.R. Kula, Cross-flow filtration in the downstream processing of enzymes, Process Biochemistry, April 1984, 67-74. 